\title{
Handbook of Research Methods in Migration
}

\author{
Edited by Carlos Vargas-Silva \\ Northampton, MA: Edward Elgar 2012 \\ ISBN 978-1849803113 \\ Hardcover, \$280.00, 608 pp.
}

\author{
Reviewed by Barry Edmonston \\ Department of Sociology and Population Research Group, University of Victoria \\ be@uvic.ca
}

This is an edited volume, organized in seven parts with twenty-seven chapters. It discusses research methods and related topics dealing with migration research. The volume is edited by Carlos Vargas-Silva, an economist who received his $\mathrm{PhD}$ from Western Michigan University, and who is a senior researcher at Oxford University's Centre on Migration, Policy, and Society. Although the volume bears the imprint of the International Migration Institute of Oxford University on its cover, suggesting a relationship with the well-known and respected Institute, the editor does not explain the relationship between it and this edited volume. The International Migration Institute's website does not list this volume as one of its publications, and the editor Carlos Vargas-Silva is not listed as affiliated with the Institute.

It should be noted at the outset that this volume deals with international migration and does not discuss internal migration. As such, it does not include methods for the collection, measurement, analysis, or interpretation of migration data within national boundaries.

This book review addresses three questions. Does the volume deliver what it promises? Is the volume useful for migration researchers? And is it useful for demographers? Regarding the first question, the editor states that the volume is intended as "a learning tool and reference for anyone interested in migration research methods" (p. 2). Moreover, the handbook aims to "maintain an introductory level of discussion in all topics and provide readers with the references necessary to go deeper into the topics" (p. 2). Unfortunately, this volume does not include the topics needed for an introductory text on migration research methods, nor is the exposition balanced at the introductory level. For example, Chapter 10 provides an excellent introductory overview of collecting migration data in household surveys; unfortunately, other chapters do not follow up with similar discussion on such related research methods as surveys for the study of emigrants, illegal immigrants, non-permanent migrants, or refugees. And there are no chapters dealing with historical, demographic, or spatial methods for migration research. Chapter 9 presents a fine example of the value of analyzing longitudinal data for the study of remittances. But it relies on fairly advanced econometric methods and would not be accessible to most readers. For introductory research methods topics, readers will want to consult other more appropriate texts.

Although this volume is intended to be interdisciplinary and international, it has an unusual distribution of authors and chapter topics. Of the forty-two authors listed in this volume, twenty-four are from North America, thirteen are from Europe, three are from Latin America, and two are from Oceania.

No chapter authors are affiliated with universities or programs in Africa, the Middle East, or Asia. Not surprisingly, most of the chapters present examples of migration in North America and Europe, with one chapter noting Mexican migration and one dealing with New Zealand and South Pacific migration. Given the importance of international migration in Africa, the Middle East, and Asia, it striking that no chapters focus on migration in these regions. The chapter authors are primarily sociologists and geographers, along with several economists. There are few contributions by scholars from different backgrounds, for example, historians, political scientists, anthropologists, or legal scholars. And strangely, for a volume on migration, there are no chapters 
written by demographers. Thus, the collection does not provide the promised international and interdisciplinary perspectives.

Is this volume useful for migration researchers? Many of the chapters in this handbook hold little interest for migration researchers. Many chapters are devoted to topics of minor value to migration researchers. For example, there are lengthy discussions of epistemological aspects of positivism versus selectivism, problems of global apartheid, Marxist critiques of "neo-liberal economic structure," and how researchers think about their early research endeavours. I identified six chapters (Chapters 3, 7, 8, 9, 10, and 12), however, that impressed with the authors' expertise, clear exposition, and usefulness specifically for migration researchers.

Chapter 3, by British sociologist David Bertram, is a stimulating argument for two propositions. First, Bertram suggests that migration researchers should place more emphasis on the study of variability. Rather than focus only on cases of high in-migration, for example, Bertram provides a convincing argument for the study of low in-migration in comparative analysis. Stated differently, analysis is improved by the inclusion of anomalous or "negative" cases. Second, Bertram proposes that researchers need a better understanding of the meaning and use of key concepts. He examines data on "immigrant labour" to show how the meaning varies in different countries and how this affects international comparisons.

Chapter 7, by Norwegian researcher Jørgen Carling, is an excellent discussion of collecting, analyzing, and presenting migration histories. It is especially valuable for its description of conventional questionnaires, life history calendars, and migration history charts for the collection of migration history data. Carling offers a rare demographic perspective in Chapter 7, noting that a Lexis diagram offers a useful tool for presenting migration histories. Overall, Chapter 7 is a valuable article for researchers collecting migration history data or dealing with their presentation.

Chapter 8, by Pomona College economists Fernando Lozano and Michael Steinberger, discuss empirical methods in economics for the study of international migration. This chapter highlights econometric techniques (ordinary least squares, binary response variable estimation, difference-in-difference approaches, instrumental variable estimation, and quantile regression) that are used in economic analysis of migration. One note of interest in Chapter 8 is the short summary of the value of migration data from natural experiments, such as the Mariel boatlift of Cubans to Miami. Their chapter provides brief, balanced summaries of how economists study several key questions: (i) immigrant assimilation into the host economy, (ii) effects of immigrant selection, and (iii) effect of immigration in local labour markets. Missing from their review, however, is the important topic of the fiscal effects of immigration.

Chapter 9, by California State University, Long Beach economist Edward Funkhouser, deals with the special topic of longitudinal data. It presents fairly advanced econometric methods for the analysis of longitudinal surveys. Funkhouser focuses on the study of remittances to provide an example of the advantages of longitudinal data. He correctly argues that longitudinal data—compared to cross-sectional data—allows researchers to follow individuals or households over time. Such data permit before-and-after analysis that can take self-selection into account. Although there are useful techniques to examine self-selection bias with cross-sectional data, theory does not provide much guidance for identifying variables that may affect self-selection. Overall, Chapter 9 provides a good discussion of how to organize, analyze, and interpret longitudinal data, albeit including more advanced econometric methods.

Chapter 10, by World Bank staff Calogero Carletto, Alan de Brauw, and Raka Banerjee, is a superb introductory overview of migration data collection from household surveys. The authors offer a balanced and informed discussion of problems in defining and measuring migration events, sampling for rare migration behaviour, and questionnaire design. This chapter's quality of technical information and clear exposition is outstanding, in stark contrast to many of the other chapters in the volume.

Chapter 12, by World Bank economists David McKenzie and Dean Yang, is an interesting and thoughtful chapter on experimental approaches to migration research. Although this chapter is not at an introductory level, it contains stimulating discussion and deserves to be read by migration researchers. Researchers are familiar with the problem of self-selection in the analysis of migration data. McKenzie and Yang discuss several papers based on the analysis of South Pacific lottery data—when the data include information on those who were selected and migrated, those who were selected but did not migrate, those who were not selected, and those who did not 
enter the lottery - and demonstrate that there is a positive selection for those who entered the lottery and, moreover, for those who decided to migrate after being selected. That there is a strong positive selection is not news to migration researchers for observable variables. But, field experimental data also reveal that there is positive selection for non-observable variables, which is an important finding for migration research. Overall, McKenzie and Yang believe that usual economic analysis from censuses and surveys overstate income gains associated with migration by about 20 per cent because they are not able to take into account non-observable positive selection.

Finally, is this volume useful for demographers? This question is easily answered. There are no chapters in this handbook that are written by demographers; nor, unfortunately, are there chapters that present demographic methods. Demographers will search in vain for any discussion of demographic data collection or analysis methods (appropriate for administrative records, censuses, surveys, or indirect estimates), double-cohort models, age-period-cohort models, immigrant generation and other population projection approaches, estimating migration flows from limited data, estimating illegal immigration, estimating emigration, and other methods that are used regularly in demographic migration research. The value of this book for demographers is limited to the six chapters described above. This is unfortunate, because a great effort must have gone into writing and producing this volume. 